\title{
Perkampungan Bahasa Arab dalam Mendukung Pembelajaran Mahasiswa di IAIN Parepare
}

\author{
Muhammad Irwan \\ Pendidikan Bahasa Arab, Fakultas Tarbiyah, IAIN Parepare \\ Email: irwandivers@gmail.com
}

\begin{abstract}
This study aims to reveal a description of learning in the Arabic village program implemented by IAIN Parepare as a reinforcement for Arabic learning. As a field research, this study is classified as a qualitative descriptive study under the approach of psycholinguistics, applied psycholinguistics and educational linguistics. The sample is students listed in the Arabic Language Village Program at IAIN Parepare. Data were collected using participatory observation methods, interviews, questionnaires, documentation and reference tracing. The results of this study reveal that the Arabic language village program at IAIN Parepare has a position as an amplifier for Arabic learning that students will face in formal courses at IAIN Parepare. The description of the learning in the program is formulated into learning methods supported by the media and learning objectives. The method used in the Arabic language village program at IAIN Parepare is a combination of several methods that focus on language learning, not language.
\end{abstract}

Keywords: Students, Learnings, Arabic Village Program

Abstrak. Studi ini bertujuan untuk mengungkapkan gambaran pembelajaran pada program perkampungan bahasa arab yang telah diimplementasikan di IAIN Parepare sebagai penguat pembelajaran bahasa arab. Sebagai penelitian lapangan, studi ini tergolong penelitian deskriptif kualitatif dengan pendekatan psikolinguistik, psikolinguistik terapan dan linguistik edukasional. Sampel adalah mahasiswa yang telah mengikuti Program Perkampungan Bahasa Arab di IAIN Parepare. Data dikumpulkan dengan metode observasi partisipatif, wawancara, kuesioner, dokumentasi dan penelusuran referensi. Hasil studi ini mengungkapkan bahwa program perkampungan Bahasa Arab di IAIN Parepare memiliki posisi sebagai penguat bagi pembelajaran bahasa Arab yang akan dihadapi mahasiswa di dalam mata kuliah formal di IAIN Parepare. Gambaran pembelajarannya pada program tersebut diformulasikan ke dalam metode pembelajaran yang didukung oleh media, dan tujuan pembelajaran. Metode yang digunakan di dalam program perkampungan bahasa Arab di IAIN Parepare adalah gabungan beberapa metode yang terfokus kepada pembelajaran bahasa, bukan tentang bahasa.

\section{Kata Kunci: Mahasiswa, Pembelajaran, Perkampungan Bahasa Arab}

\section{PENDAHULUAN}

Pembelajaran yang telah dirancang dengan baik belum mampu menjamin keberhasilan suatu program pembelajaran, karena masih banyak faktor-faktor lain yang harus diperhatikan oleh pengajar, salah satu di antaranya adalah proses pembelajaran. Dalam proses pembelajaran bahasa Arab hampir setiap pengajar pernah menemukan suasana kelas yang tidak kondusif. Pengajar merasa sia-sia karena tidak diperhatikan dan direspon baik oleh peserta didiknya. Menurut pengamatan peneliti, hal ini terjadi karena pada umumnya para pengajar dan peserta didik terjebak pada struktur kalimat dan kebahasaan sehingga timbul persepsi bahwa belajar bahasa Arab itu sulit yang mengakibatkan peserta didik mengalami kesulitan untuk memahami bahasa dan mengaplikasikannya dalam komunikasi sehari-hari.

Hal ini dapat diamati pada peserta didik yang umumnya tidak mampu berkomunikasi sehari-hari dengan menggunakan kalimat yang sederhana dalam bahasa Arab setelah proses pembelajaran selama beberapa semester. 
Oleh karena itu, paradigma peserta didik tentang pembelajaran bahasa Arab yang sulit dan membosankan harus dirubah menjadi kesan yang mudah dan menyenangkan dengan merekonstruksi dan memformat materi, metode, media, dan tujuan pembelajaran yang monoton menjadi lebih aktif dan menyenangkan. Dalam hal ini, pengajar harus aktif menyikapi permasalahan yang sedang dialami oleh peserta didik, yaitu rasa bosan dan kesan monoton. Oleh karena itu, pengajar harus mencari "formula" yang inovatif dan efektif untuk membangkitkan motifasi peserta didik dalam pembelajaran bahasa Arab.

Program Perkampungan Bahasa Arab merupakan salah satu formula dalam pembelajaran bahasa Arab yang mengacu pada kaidah-kaidah tersebut dengan sebuah program "menginap" yang menerapkan metode pembelajaran terfokus pada penguasaan kosakata -sebagai langkah awal- dengan pola kalimat sederhana yang terstruktur dan berproses ke struktur yang komprehensif dengan tujuan peserta didik diarahkan untuk memperoleh kemahiran muhadatsah.

Oleh karena itu, Sekolah Tinggi Agama Islam Negeri (IAIN) Parepare Sebagai salah satu perguruan tinggi Islam memberikan perhatian pada program tersebut sebagai upaya peningkatan pembelajaran bahasa Arab. Hal ini dapat dilihat dari dukungan moril dan materil dari IAIN Parepare yang memberikan kesempatan kepada Program Studi pendidikan Bahasa Arab (PRODI PBA) sebagai salah satu Prodi pada jurusan Tarbiyah dan Lintasan Imajinasi Bahasa Mahasiswa (LIBAM) -salah satu Unit Kegiatan Mahasiswa (UKM) IAIN Parepare- untuk senantiasa eksis dalam melaksanakan kegiatan tersebut dan salah satu program kerja dalam rangka meningkatkan kemampuan mengajar dan berbahasa mahasiswa. Selain itu, IAIN Parepare kadang mengutus mahasiswa sebagai tenaga pelatih dalam penerapan program tersebut ke sekolah-sekolah, Madrasah Tsanawiyah dan Aliyah atas permintaan pihak sekolah yang bersangkutan.

Program ini memiliki kedudukan hanya sebagai pendukung pembelajaran formal, tapi memiliki suatu ciri khas dibandingkan dengan beberapa program pembelajaran bahasa Arab (baik pembelajaran formal maupun nonformal lainnya) yang diterapkan di IAIN Parepare. Misalnya al-tariqat al-mubasyarah atau metode langsung (direct Method) dengan pengembangan dan modifikasi yang disesuaikan dengan kondisi lingkungan IAIN Parepare, lalu dipadukan dengan media dan berbagai aktifitas pembelajaran yang aktif, inofatif, komunikatif, efektif dan menyenangkan (PAIKEM) untuk dapat mendukung keberhasilan pengajaran bahasa Arab. Dengan demikian, studi ini bertujuan untuk mengungkapkan program perkampungan bahasa arab yang telah diimplementasikan di IAIN Parepare yang disajikan dalam metode pembelajaran, media pembelajaran, dan tujuan pembelajaran

\section{METODE}

Penelitian ini adalah penelitian lapangan (field research) dan jenis penelitian ini adalah "deskriptif kualitatif", yaitu data yang diperoleh berupa kata-kata, gambar, perilaku, tidak dituangkan dalam bentuk bilangan atau angka statistik melainkan tetap dalam bentuk kualitatif yang memiliki arti lebih kaya dari sekedar angka atau frekuensi.

Pemilihan metode ini dimaksudkan untuk memberi gambaran secermat mungkin mengenai Program Perkampungan Bahasa Arab. Penelitian kualitatif ini dipilih sesuai dengan tujuan yang ingin dicapai yaitu mendiskripsikan dan melihat kemampuan program perkampungan Bahasa Arab dalam memacu mahasiswa IAIN Parepare (dulunya STAIN Parepare) dalam bercakap bahasa Arab, dan untuk menggambarkan materi, metode, media, dan tujuan dalam mendesain pembelajaran bahasa Arab yang lebih menarik bagi peserta (musytarik) Program Perkampungan Bahasa Arab sehingga peserta didik lebih nyaman dan semangat dalam proses program pembelajaran, serta mengungkapkan masalahmasalah yang berkaitan dengan program Perkampungan Bahasa Arab sebagai salah satu upaya untuk memotivasi dan menghilangkan kejenuhan mahasiswa dalam belajar bahasa Arab.

Disiplin pendekatan yang peneliti gunakan adalah pendekatan sosiolinguistik yang merupakan disiplin ilmu untuk mengetahui 
teknik berinteraksi antara pengajar dan peserta didik.

Adapun sampel adalah peserta Program Perkampungan Bahasa Arab IAIN Parepare. Proses pengolahan dan analisis data dalam penelitian dilakukan melalui tiga tahapan secara berkesinambungan yang meliputi tahap reduksi data (data reduction), tahap penyajian data (data display), dan tahap penarikan kesimpulan/verivikasi drawing/verivication).

\section{HASIL DAN PEMBAHASAN}

Pembelajaran bahasa mengandung makna belajar melalui bahasa dan belajar tentang bahasa. Pengembangan bahasa pada peserta didik memerlukan kesempatan untuk menggunakan bahasa. Oleh karena itu, dibutuhkan lingkungan belajar yang memberikan kesempatan yang banyak kepada peserta didik untuk menggunakan bahasa secara fungsional (Pinnell, Gay Su \& Myna, 1986).

Pada dasarnya perkembangan metode pembelajaran bahasa hanya berkisar pada dua metode saja, yaitu metode yang mementingkan penguasaan bahasa lisan secara aktif dan metode yang mementingkan penghafalan aturan-aturan gramatika (Sumardi, 1975).

Sebagaimana dengan metode, baik buruknya suatu teknik pembelajaran keterampilan berbahasa tidak terletak pada teknik pembelajaran. Apabila seorang pembelajaran menggunakan suatu teknik dalam konteks yang tepat, misalnya sesuai dengan tujuan dan bahan pembelajaran, maka jadi baiklah teknik pembelajaran tersebut. Sebaliknya, apabila seorang pengajar tidak tepat menggunakannya maka teknik pembelajaran tersebut menjadi jelek. Karena itu, dapat disimpulkan bahwa teknik pembelajaran pada umumnya dan teknik keterampilan berbahasa pada khususnya bersifat netral (Tarigan \& Tarigan, 1990).

Penggunaan media dalam pembelajaran bahasa Arab bertitik tolak dari teori yang mengatakan bahwa totalitas persentase banyaknya ilmu pengetahuan, keterampilan, dan sikap yang dimiliki oleh seorang terbanyak dan tertinggi melalui indra lihat dan pengalaman langsung melakukan sendiri, sedangkan selebihnya melalui indra dengar dan indra lainnya (Arsyad, 2009).

\section{Metode Pembelajaran}

Dalam membahas metode pembelajaran tidak dapat dipisahkan dari pendekatan dan teknik pembelajaran. Ketiga hal tersebut memiliki hubungan yang erat, teknik merupakan suatu hasil dari metode yang selalu konsisten dengan pendekatan.

Berpijak pada prinsip-prinsip pembelajaran secara empiris. Program perkampungan Bahasa Arab di IAIN Parepare menganut pendekatan komunikatif yakni pembelajaran bahasa Arab yang diarahkan kepada penggunaan bahasa dalam situasi "nyata" maupun "simulasi kehidupan nyata", meskipun pada proses pembelajaran lebih banyak dilakukan di luar kelas. Dengan demikian, program ini bertujuan untuk membekali peserta menggunakan bahasa Arab sebagai bahasa sehari-hari yang selanjutnya dapat menjadi salah satu motivasi untuk mempelajari bahasa Arab secara mandiri.

Oleh karena itu, metode yang digunakan di dalam program perkampungan bahasa Arab di IAIN Parepare adalah gabungan beberapa metode yang terfokus kepada pembelajaran bahasa, bukan tentang bahasa. Di antaranya yakni metode langsung, metode alamiah, metode psikologi, dan metode fonetik. Hal ini dapat dilihat dari susunan materi untuk mempermudah peserta menggunakan bahasa Arab sebagai bahasa komunikasi. Selain itu materi yang ada pada umumnya disajikan oleh tim pengajar dalam bentuk simulasi atau permainan menarik yang bertujuan untuk mengaktifkan seluruh panca indra dan melibatkan emosi peserta didik agar dapat menuturkan pikirannya dalam bahasa Arab.

Dalam pengaplikasian metode yang digunakan para pengajar memiliki ciri khas dan teknik masing-masing. Namun, pendekatan dan metode yang baik akan sinergi jika digunakan oleh pengajar yang terampil dan kreatif sehingga dapat menciptakan suasana belajar yang aktif, inovatif, kreatif, efektif dan menyenangkan.

Menurut pengamatan peneliti proses pembelajaran di dalam program perkampungan bahasa Arab bukan hanya terhitung pada saat 
tatap muka di dalam kelas atau didampingi oleh tim pengajar di luar kelas. Akan tetapi lebih dari itu, selama dalam kegiatan itu termasuk proses pembelajaran bahasa Arab. Bahasa yang mereka peroleh pada tatap muka di kelas maupun bimbingan di luar kelas diaplikasikan dalam kehidupan peserta yang terkontrol. Meskipun kadangkala terdapat di antara peserta yang tidak konsisten menggunakan bahasa Arab baik dengan menggunakan bahasa Indonesia maupun dengan bahasa daerah mereka.

\section{Media Pembelajaran}

Dalam proses pembelajaran, sering kali peserta didik sampai pada titik jenuh, terutama bila hanya menerima pesan melalui lisan saja. Oleh karena itu, kehadiran media pembelajaran sangat dibutuhkan dalam situasi seperti ini, karena dapat memotivasi peserta didik untuk lebih memperhatikan penjelasan pengajar dan materi yang disajikan lebih menarik, tidak hanya melalui lisan tetapi juga melalui pesan visual atau audio-visual.

Media merupakan sarana yang dapat membantu peserta didik dalam memahami setiap penjelasan yang diberikan oleh pengajar. Dengan media, pengajar dapat menjelaskan hal-hal yang kompleks dan dapat menjelaskan sesuatu lebih nyata agar lebih mudah diamati secara lebih utuh. Hanya saja, penggunaan media pada umumnya masih mengalami kendala ketika sebuah lembaga belum mampu menyediakannya dalam proses pembelajaran.

Sehubungan dengan hal di atas, IAIN Parepare sebagai lembaga yang menaungi Program Perkampungan Bahasa Arab di IAIN Parepare berusaha memenuhi hal tersebut untuk menunjang dan mengefektifkan proses pembelajaran, walaupun belum maksimal.

\section{Tujuan Pembelajaran}

Tujuan dan tingkatan tujuan pembelajaran bahasa sebagai alat komunikasi tersebut menjadi salah satu acuan dalam pembelajaran bahasa pada berbagai situasi pembelajaran. Di samping itu, tujuan pembelajaran bahasa biasanya mencerminkan aspek-aspek tertentu dari kompetensi komunikatif yang sesuai dengan kemahiran dan kebutuhan peserta didik.
Sebagaimana telah digambarkan sebelumnya bahwa tujuan pembelajaran Program perkampungan bahasa Arab di IAIN Parepare tidak terlepas dari fungsi Bahasa sebagai alat komunikasi. Oleh karena itu, tujuan utama dari program ini adalah untuk memberikan motivasi belajar kepada peserta melalui penggunaan bahasa Arab sebagai bahasa sehari-hari sehingga dapat mencetak peserta didik yang memiliki rasa percaya diri yang tinggi dalam belajar bahasa Arab.

Hal ini sesuai dengan yang dikatakan Ketua Program Bidang Studi Pendidikan Bahasa Arab H. Muhammad Iqbal Hasanuddin, M. Ag., Bahwa:

Program ini memiliki orientasi untuk meningkatkan motivasi peserta dalam mempelajari bahasa Arab melalui percakapan sehari-hari, meskipun masih bersifat lokal di lingkungan mereka, namun diharapkan dapat mengantarkan peserta untuk dapat memahami penutur asli melalui media audio-visual dan dapat mengembangkan pembelajaran bahasa Arab. Adapun tujuan perkampungan bahasa Arab dapat dibedakan menjadi dua adalah sebagai berikut.

1) Tim Pengajar:

a) Melatih mahasiswa sebagai tenaga pengajar yang mampu mengajar dan menciptakan pembelajaran yang aktif, inovatif, kreatif, efektif, dan menyenangkan dalam pembelajaran bahasa Arab.

b) Melestarikan dan mengembangkan Program Perkampungan Bahasa Arab di IAIN Parepare sebagai salah satu program pembelajaran yang ditawarkan oleh Jurusan Tarbiyah IAIN Parepare.

2) Peserta:

a) Peserta mampu menghafal perbendaharaan kata populer sekurangkurangya 500 mufradat serta mampu mengaplikasikannya percakapan seharihari.

b) Peserta mampu memahami aspek fungsional dan komunikatif bahasa Arab dalam berkomunikasi pada berbagai konteks yang berbeda-beda melalui penguasaan perbendaharaan kata populer. 
c) Peserta mampu memahami dan menyimak teks muhadatsah lisan dan tulisan yang mereka terima, dan memberikan respon terhadap teks tersebut secara oral ataupun tertulis.

d) Peserta mampu menjadikan bahasa Arab yang dikuasainya sebagai media pengembangan potensi dan kapasitas yang dapat dijadikan sebagai motivasi dan rasa percaya diri yang tinggi dalam belajar bahasa Arab.

Tujuan-tujuan tersebut menjadi acuan pelaksanaan pembelajaran Program perkampungan Bahasa Arab. Akan tetapi, dalam perkembangannya masih ada pengajar yang masih jauh dari tujuan tersebut dalam memberikan materi. Khususnya dalam penggunaan bahasa Arab sebagai bahasa pengantar dalam proses pembelajaran. Sehingga kadang kala peserta tidak konsisten dalam menggunakan bahasa Arab kecuali jika di hadapan pengajar.

Selain itu, dalam kaitannya dengan materi pembelajaran yang belum terdokumentasikan secara tertulis dan sistematis dalam bentuk silabus mengakibatkan pengajar kadang kala melenceng dari tujuan pembelajaran dan memberikan materi secara tidak sistematis pula dan materi kadang kala dirumuskan oleh kesepakatan tim pengajar sebelum dan setelah tiap-tiap sesi pembelajaran.

Sehubungan dengan tujuan peserta yakni kemampuan untuk dapat menguasai kosa kata bahasa Arab dan mengaplikasikannya dalam kehidupan sehari-hari dapat tercapai, meskipun percakapan mereka masih bersifat lokal, baik dari penggunaan kosakata, struktur, maupun dialek. selain itu, program ini mampu memacu motivasi mereka dalam belajar bahasa Arab dan dapat membuka cakrawala pikir mereka bahwa pembelajaran bahasa Arab dapat dilakukan dengan cara-cara yang aktif, inovatif, komunikatif dan menyenangkan.

\section{KESIMPULAN}

Program Perkampungan Bahasa Arab di IAIN Parepare dapat berlangsung dengan baik tidak lepas dari hal pendukung yang telah ada yaitu cukup mendapat respon dari unsur pimpinan, dan jajarannya; Sebagian mahasiswa mempunyai latar belakang pendidikan dari madrasah dan pesantren, sehingga mereka punya pengetahuan tentang bahasa Arab; Pengajar yang berasal dari Program Studi Pendidikan Bahasa Arab dan telah mengikuti dan dilatih menjadi pengajar program tersebut.

Desain pembelajaran bahasa Arab komunikatif pada Program Perkampungan Bahasa Arab di IAIN Parepare bertujuan untuk memberikan motivasi belajar kepada peserta melalui penggunaan bahasa Arab sebagai bahasa sehari-hari sehingga dapat mencetak peserta didik yang memiliki rasa percaya diri yang tinggi dalam belajar bahasa Arab melalui penguasaan perbendaharaan kata populer, dan pelatihan menyimak dan merespons tes lisan dan tulisan. Pada program ini belum ada silabus tetap dan tertulis secara sistematis sehingga pengajar hanya berpedoman pada pelatihan-pelatihan yang diterima secara langsung dari "pengajar senior" dan pembina serta pengembangan dari pengalaman-pengalaman pembelajaran sebelumnya yang tetap mengacu pada tujuan pembelajaran. Dalam hal aktivitas belajar mengajar, aktivitas belajar mengajar diarahkan dengan metode langsung, metode alamiah, metode psikologi, dan metode fonetik yang dipadukan dengan media pembelajaran yang tertuju kepada pembelajaran yang aktif, inovatif, komunikatif, efektif dan menyenangkan (PAIKEM). Dalam hal ini, pengajar bertindak sebagai fasilitator di antara peserta yang bernegosiator meskipun masih ada di antara peserta yang pasif sebagai impilikasi di antara pengajar yang belum mampu mengolah pembelajaran tersebut. Terlepas dari berbagai kendala-kendala yang dihadapi, bisa dikatakan bahwa komponen-komponen pembelajaran tersebut telah bersinergi dalam memacu peserta untuk berkomunikasi dalam bahasa Arab.

\section{SARAN}

Program Perkampungan Bahasa Arab di IAIN Parepare (dulunya STAIN Parepare) merupakan suatu proses yang kompleks yang masih perlu dibenahi dan dikelola secara profesional, agar desain pembelajaran bahasa Arab pada program tersebut dapat lebih sistematis yang tersinergikan dengan metode, media, dan tujuan sehingga peserta termotivasi 
dalam belajar serta mampu mengimplementasikan aspek fungsional bahasa Arab sebagai bahasa komunikasi dalam lingkungan kampus.

Untuk mencari sebuah pola dan sistem yang dapat mencapai hal ini memang tidak mudah, tetapi dengan memperhatikan dan beberapa kendala-kendala dalam Program Perkampungan Bahasa Arab di IAIN Parepare, maka diharapkan dapat menjadi salah satu acuan dan pedoman dalam merancang program pembelajaran bahasa Arab yang berlaku di PTAIN, khususnya di IAIN Parepare dalam rangka mengefektifkan pembelajaran bahasa Arab.

\section{DAFTAR PUSTAKA}

Arsyad, Azhar. (2009). Media Pembelajaran, Ed. Asfah Rahman. Jakarta: Rajawali Pers.

Rayyani, W. O., \& Abbas, A. (2020). Akuntabilitas Kinerja dalam Bingkai Tauhid Sosial: Suatu Refleksi Teologi Al Ma'Un. Kamaya: Jurnal Ilmu Agama, 3(2), 174-190.

Pinnell, Gay Su dan Myna L. Maltin. (1986). Teachers and Research Language Learning in The Classroom Newark: IRA.

Sumardi, Muljanto dan AR Partosentono. Pedoman Pengajaran Bahasa Arab pada Perguruan Tinggi Agama /IAIN. Jakarta: Proyek Pengembangan Sistem Pendidikan Agama DEPAG RI.

Sumardi, Muljanto. (1975). Pengajaran Bahasa Asing. Cet. II; Jakarta: Bulan Bintang.

Tarigan, Henri Guntur. (1991). Strategi Pengajaran dan Pembelajaran Bahasa, Cet. X; Bandung: Angkasa.

Tarigan, Djago dan H. G. Tarigan. (1990). Teknik Pengajaran Keterampilan Berbahasa. Cet.I; Bandung: Angkasa. 